\title{
DA AÇÃO PEDAGÓGICA À MUDANÇA DA PRÁTICA DOCENTE: OS JOGOS E AS BRINCADEIRAS EM UMA EXPERIÊNCIA COM O EN- SINO MÉDIO
}

\author{
Vânia de Fátima Matias Souza \\ Universidade Estadual de Maringá, Maringá, Paraná, Brasil \\ Luciane Cristina Arantes da Costa \\ Universidade Estadual de Maringá, Maringá, Paraná, Brasil \\ Ana Luiza Barbosa Anversa \\ Universidade Estadual de Maringá, Maringá, Paraná, Brasil \\ Sandra Maria Moreira \\ Universidade Estadual de Maringá, Maringá, Paraná, Brasil
}

\begin{abstract}
Resumo
Teve-se como objetivo apresentar o trabalho interdisciplinar realizado junto aos professores do Ensino Médio de uma escola do noroeste do Paraná, com foco nasreflexões e mudanças provocadas na prática docente a partir do trabalho com jogos e brincadeiras. Realizou-se um grupo focal comprofessores de diferentes disciplinas, em que as discussões se direcionaram para a possibilidade de intervenção e aplicação dos conteúdos por meio do jogo.De inicio, os alunos indicavam que as aulas e conteúdos eram cansativos e aprendizagem era dificultada, já com o uso de jogos e brincadeiras, obteve-se maior dinamismo resultando em maior interesse dos alunos nas aulas, denotando que quando são oportunizados a participar e interagir tornamse mais integrados e interessados,enaltecendo o trabalho coletivo.
\end{abstract}

Palavras-chave: Educação Física Escolar. Ação Pedagógica. Processo de EnsinoAprendizagem

\section{Introdução}

A conscientização sobre a ordem social vigente e a possibilidade de promover ações que levem à transformação da forma hegemônica é uma discussão comum no ambiente escolar, uma vez que esta, ao assumir-se como transmissora dos conteúdos científicos e sistematizados, pode auxiliar nesse processo, propondo a elaboração de um Projeto Político Pedagógico pautado na totalidade e nas contradições das relações societárias de classes.De acordo com Alves (2005), a escola depende da organização do trabalho pedagógico, que deve se pautar em uma relação educativa que confronte a história do educador com a do educando, utilizando para isso procedimentos técnico-pedagógicos, tecnologias educacionais e conteúdos programáticos.

A escola da atualidade apresentauma realidade de mudanças constantes, de necessidades volúveis e, que por vezes, acaba gerando inquietações, dúvidas e conflitos, tanto de alunos quanto dos professores, com relação ao papel da escola e como deve acontecer o processo de ensino-aprendizagem. Junto a essas dúvidas surgem inúmeras outras questões, a exemplo: o que a escola deve ensinar? São as novas tecnologias o problema? São os alunos desinteressa- 
dos com as questões sociais e humanas tratadas no ambiente escolar? Estaria o problema na formação dos professores? Ou, ainda, as questões escolares estão sempre atreladas às dificuldades dos alunos? Comolidar com a falta de interesse, concentração e motivação dos alunos, em especial do ensino médio, para com as atividades as atividades propostas?

A partir dessas inquietudes cotidianas no ambiente escolar e observando a diferença entre as ações e atitudes dos alunos nas aulas de educação física, comparado às demais disciplinas da grade escolar, algumas questões nos inquietaram: será que ao incluir o jogo e o brincar, nas aulas dos diversos componentes curriculares, seria possível provocar uma mudança de atitude por parte dos alunos, levando-os a buscarem ampliar seus horizontes acerca da relevância dos conteúdos escolares?Como os alunos, já na adolescência, atendem ao trabalho escolar em que se enfatiza a situação-problema e suas possibilidades? Será que ao sair das aulas no modelo 'tradicional' de ensino e buscar as questões problemas, o jogar e o brincar enfrenta maior dificuldade por parte dos alunos ou dos professores? Quais seriam as maiores barreiras e de onde vêm os maiores paradigmas de uma educação escolar fragmentada, na qual o uso das carteiras ainda se faz uma realidade constante na sala de aula?

Tendo esse panorama instaurado, o texto tem como objetivo apresentar o trabalho interdisciplinar realizado junto aos professores do Ensino Médio de uma escola da rede pública do noroeste do Paraná, como possibilidade de se integrar e inserir o adolescente nas discussões dos conteúdos escolares, por meio do jogar e do brincar pedagógico nas aulas, trazendo a integração da Educação Física de forma efetiva junto às demais disciplinas. Para tanto, buscou-se discutir junto aos professores os subsídios teóricos das metodologias propostas e estratégias de ensinoque possibilitassem atender as demandas do Projeto Pedagógico, com intuito de potencializar o desencadeamento de ações que visem mudanças de atitudes na prática interventiva do professor e promova o maior interesse por parte dos alunos.

\section{A prática pedagógica e o processo educativo}

Defensor dos estudos de Vygotsky, Ivice Coelho (2010) declaram que o homem é um ser essencialmente social; impossível, portanto, de ser pensado fora do contexto da sociedade em que nasce e vive, uma vez que o ser humano é social (VYGOTSKY, 1998), porque logo ao nascer já é inserido em um grupo social e cultural a família, que lhe transmite uma série de normas vivenciais, bem como a linguagem e outros valores. Tanto a família como a escola humaniza o homem à medida que transmitemos valores por meio do convívio social. A comunidade, com suas maneiras de ser e seus costumes, procura ajustar o indivíduo, apresentando normas de vida que, geralmente, devem ser acatadas.

De acordo com o modelo Histórico-Cultural, os traços de cada ser humano estão intimamente relacionados ao aprendizado, à apropriação do legado do seu grupo cultural. $\mathrm{O}$ comportamento e a capacidade cognitiva de um determinado indivíduo dependerão de suas experiências, de sua história educativa, que, por sua vez, sempre terão relações com as características do grupo social e da época em que ele se insere. Assim, "a singularidade de cada indivíduo não resulta de fatores isolados, mas da multiplicidade de influências que recaem sobre o sujeito no curso do seu desenvolvimento" (REGO, 2002, p. 50).

De acordo com Vygotsky (1998, p.70), "na educação [...] não existe nada de passivo, de inativo. Até as coisas mortas, quando se incorporam ao círculo da educação, quando se lhes atribui papel educativo, adquirem caráter ativo e se tornam participantes ativos desse processo." Por meio do lúdico, do jogar e do brincar, supõe-se que o aluno possa ter condições de refletir, agir e pensar sobre sua ação em situações coletivas. Palma et al. (2015) ressalta que o uso do jogo no contexto da educação formal vem a auxiliar na aprendizagem, uma vez que os alunos ficam mais atentos e relaxados, mobilizando saberes, conferindo significado aos estímulos dados pelo professor. 
Esta intenção lúdica proporciona aos educandos a descoberta de si e do mundo a sua volta, possibilitando aprender com o erro, com o acerto ou com o outro, ampliandoa possibilidade de tomada de decisão, seja numa situação escolar ou fora dela, contribuindo para a socialização e motivação no processo de ensino aprendizagem (NASCIMENTO et al., 2012).

Ressalta-se que uma ação pedagógica voltada para participação ativa dos educandos e o caráter lúdico não é uma realidade constante no ambiente escolar, em especial no ensino médio. Neste contexto,os alunos são vistos como inconsequentes, desatentos e desinteressados, entretanto, faz-se necessário pensar se estes não são reflexos de estímulos rápidos e superficiais, que os levam a se sentirem desconfortáveis quando solicitados em atividades de exposição social, como por exemplo, discutir conhecimentos sobre determinados saberes escolares.

Por fim, vale destacar, de acordo com os Parâmetros Curriculares Nacionais (PCNs), que o uso de jogos lúdicos em sala de aula pode ser um mediador entre conteúdo e cotidiano. Santos (2006a), Pimentel (2006) e Santana (2012) destacam que este recurso facilita o desenvolvimento do sistema cognitivo por meio de discussões e resoluções de problemas, o que repercute no significado ou importância do conhecimento científico, mas para que isso ocorra, as ações devem ser bem planejadas e organizadas pelos professores traçando objetivos específicos a serem alcançados e estratégias desafiadoras para envolver os alunos.

\section{Caminho percorrido}

Para o desenvolvimento deste estudo, optou-se pela realização de uma pesquisa de cunho qualitativo, com um grupo focal junto aos professores participantes da pesquisa e aplicação de questionário aos alunos com questões abertas, para que os mesmos apontassem as mudanças constatadas no desenvolvimento dos conteúdos a partir dos jogos e brincadeiras.

Chizzotti (2006, p. 28-29) aponta que o uso do grupo focal

[...] implica uma partilha densa com pessoas, fatos e locais que constituem objetos de pesquisa, para extrair desse convívio os significados visíveis e latentes que somente são perceptíveis a uma atenção sensível. Após este tirocínio, o autor interpreta e traduz em um texto zelosamente escrito, com perspicácia e competências científicas, os significados patentes e ocultos do seu objeto de pesquisa.

Assim, por meio desta ferramenta, é possível compreender os valores, opiniões, crenças e atitudes que sustentam a postura, a visão de mundo e as relações entre os sujeitos envolvidos, e a significação que esses atribuem ao fato estudado, consistindo em instrumento fundamental para desvelar a complexidade da realidade investigada. Gatti (2005) complementa ao apontar que o grupo focal permite compreender processos da construção da realidade e práticas cotidianas, constituindo uma técnica importante para o conhecimento das representações, percepções, hábitos e valores.

Não se tem a pretensão de transformar a metodologia de aula dos professores, mas possibilitar que os mesmos possam refletir sobre possibilidadespara "o ensinar", instrumentalizando-ospela pesquisa e possibilitando desenvolver uma prática reflexiva acercados acontecimentos que se dão em sala de aula, de forma a buscar a sua compreensão, para desenvolver ações docentes concretas e efetivas que atendam aos inúmeros desafios do cotidiano escolar. Santos (2006b) enfatiza a necessidade de formar docentes questionadores, investigadores, reflexivos e críticos, que se posicionem ativamente por meio de ações emancipatórias, autônomas e criativas. $\mathrm{O}$ uso do questionário para os alunos se justificapor ser uma ferramenta que possibilita diagnosticar e aperfeiçoar o processo de ensino-aprendizagem, por meio do levantamento de informações (BARROS; LEHFELD, 2000; ROJAS, 2001). 
Nessa perspectiva, foram convidados a compor o grupo focal dez professores de uma escola do noroeste do Paraná, que atuam nas disciplinas de Educação Física, Biologia, Administração, Arte, Filosofia, História e Pedagogia do Ensino Médio e Ensino Médio Profissionalizante. Foram realizados encontros semanais com duração quatro horas, durante o primeiro semestre do ano letivo de 2015. Estes encontros se propuseram a integrar as aulas de Educação Física às demais disciplinas, trabalhando as possibilidades do lúdico como instrumento metodológico, uma vez que por meio deste é possível induz a motivação e diversão; proporcionar integração social; auxiliar no desenvolvimento do senso crítico; estimular a criatividade; proporcionar a liberdade de expressão e promover o interesse pelo conteúdo e a participação de forma natural.

Como estratégia de estruturação, buscou-se em um primeiro momento discutir as aproximações e distanciamentos entre as disciplinas e as possibilidades de relacionar os conteúdos curriculares aos jogos e brincadeiras a partir das contribuições do campo da Educação Física. Foram debatidos com os professores músicas e textos sobre o cotidiano escolar, o processo de ensino aprendizagem, e as possibilidades de intervenção por meio de jogos e brincadeiras, e a partir de então foi estruturado de forma coletiva o planejamento das ações. Tendo vencido as discussões acerca dos conteúdos, os professores de Educação Física envolvidos, propuseram ações e atividades que pudessem integrar os conteúdos das diversas áreas por meio das atividades que poderia melhor se adequar às necessidades das áreas. Como atividades a serem desenvolvidas em sala relacionando o conteúdo com jogos e brincadeiras foi estruturada a introdução ao xadrez, na qual os alunos seriam as peças do tabuleiro e cada personagem teria uma forma de deslocamento. Esta atividade inter-relacionaria conhecimentos de história (história medieval - funções do rei, rainha, torre, cavaleiros, posições hierárquicas), matemática (raciocínio lógico, cálculos matemáticos para os deslocamentos, formas geométricas, atenção) e educação física (imaginação, elementos corporais, deslocamentos, respeito às regras, relacionamento interpessoal). A outra atividade foi "encontre seu par", na qual por meio de perguntas e respostas, os alunos deveriam chegar ao resultado da operação proposta na brincadeira por meio de resolução de problemas. Nesta atividade é possível utilizar conhecimentos da Matemática, Geografia, Português, e Ciências.

Ao final, após as discussões e roda de conversas com os alunos, os mesmos responderam o questionário semiestruturado, elaborado pelos professores, que buscava entender a visão dos alunos quanto à prática docente utilizada. Essa proposta possibilitou que o projeto fosse desenvolvido e avaliado junto a 233 alunos, sendo 139 do sexo feminino e 84 do sexo masculino do curso do Ensino Médio e Profissionalizante. Ressalta-se que os professores participantes assinaram o Termo de Consentimento Livre e Esclarecido e que a pesquisa foi aprovada pelo Comitê de Ética em Pesquisa sob o Parecer n. 1.322.090.

\section{Refletindo a prática docente: relatos dos alunos}

Para Huizinga (1980), todo ser humano pode beneficiar-se de atividades lúdicas, uma vez que estas fomentam o desenvolvimento cognitivo, motor, social e afetivo, proporcionando a socialização, a interação e aprendizagem (FREIDMANN, 1996). O brincar não é coisa apenas de "crianças pequenas", mesmo sendo esse o equivocado paradigma da escola, que tende a dividir o universo escolar em lados opostos: de um lado, o jogo, o brincar, o sonho, a fantasia e; do outro, o "mundo sério do trabalho e do estudo".

Pensando nisso e com a experiência nas aulas de Educação Física junto ao Ensino Médio e Ensino Profissionalizante, entende-se que ao trabalhar com os jogos e brincadeiras nas práticas escolares, estamos possibilitando o desenvolvimento da imaginação, estimulando a criatividade, facilitando o aprendizado por meio da interação com o outro, uma vez que, passamos a incentivar o aluno a se tornar protagonista de sua ação e interação no ambiente 
escolar, em virtude da iniciativa e participação em grupo. Segundo Vygotsky (1998), o lúdico apresenta-se como uma possibilidade de ensino que visa à reflexão e à ligação entre o que é imaginário e o que é real.

Para Kishimoto (2005), os jogos e brincadeiras têm uma função educativa e lúdica. Em sua função lúdica, estas atividades proporcionam a diversão, o prazer e o desprazer quando escolhidos espontaneamente; na dimensão educativa as ações desenvolvidas ensinam, complementando o indivíduo em seu saber, conhecimento e apreensão do mundo. Cunha (2012) complementa ao apontar que os jogos passam de espontâneos à pedagógicos na medida em que se tem um equilíbrio entre a função lúdica e os conceitos disciplinares e situações problemas, trabalhando conhecimentos e habilidades que se apliquem no cotidiano do aluno, buscando explicações e resoluções de situações relacionadas a múltiplas temáticas como saúde, consciência ambiental, organização social, diversidade, sustentabilidade, entre outros.

Correa, Souza e Bicalho (2003) observam que no ensino médio o trabalho com jogos e brincadeirasparte da ideia de um planejamento participativo, entendendo que o brincar e o jogar podem provocar mudanças em todos os níveis de ensino. Buscou-se no primeiro momento das intervenções, verificar como os alunos analisama aplicação e desenvolvimento dos conteúdos escolares. Para análise, partiu-se da perspectiva dos atores centrais do processo: os alunos, sendo 139 do sexo feminino e 84 do sexo masculino, com idades entre 15 e 20 anos, buscando compreender qual o olhar destes sobre a figura do professor em sala de aula e seu papel no processo de aprendizagem.

As declarações suscitaram por olhares que buscam professores que interagem e permitem a maior integração entre os alunos:

[...] precisamos de professores capacitados nas salas de aula e não daqueles que "dão aula por dar" e não suportam ficar na sala de aula (EM aluno 9)

[...] Ninguém precisa ser o melhor em tudo, mas no mínimo, os professores deveriam tornar divertidas coisas simples como, por exemplo, a leitura (EM aluno 19)

[...]Os professores deveriam ser mais amigos dos alunos, ao invés de ser o poder da sala de aula (EP aluno 14)

[...]Se alguns professores mudassem o seu jeito de dar aula para um que seja mais alegre, a escola seria mais interessante (EP aluno 11)

[...]Alguns professores estragam a esperança de aprender (EP aluno 8)

Além destes apontamentos, constatou-se a partir do questionário que $60 \%$ dos alunos têm interesse pelas disciplinas e pelos conteúdos que são trabalhados no Ensino Médio; 33\% se interessam em partes, dependendo do professor e de como eletrabalha o conteúdo; e, $7 \%$ não se interessam pelas disciplinas afirmando não entenderem a função das disciplinas e sua contribuição para a sua formação humana ou pessoal. Dos alunos que se interessam pelas disciplinas, destaca-se que:

[...]as disciplinas de lógica matemática são necessárias para conhecer as matérias e tirar boa nota no vestibular (EM aluno 1)

[...]quanto mais se aprende melhor, para ter conhecimento, as disciplinas são construtivas e me ajudam a escolher minha profissão (EM aluno 2)

[...] as aulas de educação física nos fazem aprender coisas do mundo sem ser de um jeito chato (EM aluno 3)

[...] faz raciocinar e usar a lógica, para adquirir conhecimento social e cultural, são coisas que usará na vida, porque uso em casa tudo que aprendo e quero me profissionalizar, tenho amor pela profissão de educador, aprendo sobre as crianças (EPaluno 4)

[...]para tirar notas e passar de ano (EP aluno 6) 
A afirmativa do aluno em relação à educação física aproxima-se das discussões realizadas por Darido et al. (1999), em que,no ensino médio, a Educação Física implica na promoção da reflexão por meio do conhecimento sistematizado, por apresentar reflexões acerca de um conjunto de práticas corporais e uma série de conceitos que permitem o desenvolvimento da criança. Essa análise vai ser encontrada na fala e fazer recorrente junto aos alunos quando questionados com relação à educação física e para as demais disciplinas da grade curricular do ensino médio. Dos alunos que responderam que apresentam pouco interesse pelos conteúdos escolares, destacamos alguns relatos, sendo:

[...] algumas disciplinas tem muitas horas para pouco conteúdo, metade das disciplinas são chatas, algumas coisas são desnecessárias(EP aluno 8)

[...] professores deixam a desejar, existem professores inteligentes, mas não conseguem passar esse conhecimento(EP aluno 9)

[...] depende do jeito que a disciplina é passada, gosto apenas de matemática e língua portuguesa porque são mais legais, alguns professores não sabem dar aula, alguns gostam de sua disciplina masalguns não vão muito bem (EM aluno 4)

[...] apenas nas aulas de Artes, Educação física e Biologia descobrimos mais coisas (EM aluno 9)

[...]alguns professores apenas querem passar o conteúdo esquecendo de entretenimento para maior fixação e quando o professor não interage com a gente, fica ainda mais difícil aprender e prestar atenção e por isso se desinteressa (EM aluno 12)

Em um estudo de Faria e Moura (2015), os relatos apontaram como motivos da desistência dos alunos no ensino de jovens e adultos: a metodologia de ensino inadequada não compatível com o nível da turma; o ritmo excessivo de atividades em sala de aula; e o despreparo dos professores para lecionar na modalidade. Dados esses que vão se assemelhar aos que foram encontrados neste estudo, uma vez que quando os alunos foram questionados acerca da metodologia da aula, 55\% afirmaram que preferem aulas por meio de dinâmicas, jogos e brincadeiras; $23 \%$ preferem aula expositiva; $16 \%$ preferem exercícios de fixação e apenas $6 \%$ afirmaram ser indiferente a metodologia utilizada pelo professor.

[...] quando o professor usa os jogos nas aulas a gente aprende muito, os professores explicam bem, e a gente consegue aprender bem (EM aluno 14)

[...] com o uso das brincadeiras os professores dão muitas atividades e diversificam as aulas, diferente de quando ele só dita ou passa lista de exercícios, porque aí não existem muitas alternativas (EM aluno 15)

Esses depoimentos vão ao encontro da afirmativa de Dantas, Paiva e Barbosa Júnior (2007, p. 87), ao relatarem que para atuação com adolescentes e jovens se faz necessário "a organização dos tempos e espaços adequados a cada realidade, considerando as peculiaridades existentes; pois do contrário passa-se a ter a desmotivação e o abandono voluntário do universo escolar."

[...] o sistema de ensino deveria estar mais relacionado às tecnologias, faltam materiais didáticos, alunos não respeitam o professor, aprendem coisas que não usam na vida, só no vestibular (EP aluno 13)

[...] necessita-se de maior interação entre aluno e professor, os alunos não colaboram, alguns professores não explicam direitoe isso acaba fazendo um sistema é fraco (EP aluno 14)

[...] o sistema de ensino é precário, algumas aulas são chatas, alguns professores não gostam do que fazem e são mal-humorados, desmotivando os alunos (EM aluno 15) [...] o sistema está atrasado para a juventude, nem sempre prende a atenção, não supre a necessidade de todos, alguns professores deveriam se esforçar mais e dar mais atenção aos alunos, falta dinamismo, os alunos se distraem durante as aulas, precisa de outros métodos, necessita de aulas mais dinâmicas (EM aluno 16) 
[...] o sistema avaliativo são falhos e não reflete o conhecimento do aluno, as aulas deveriam ser fora da sala, alguns professores fazem de suas aulas algo sem importância, não levam os alunos a sério (EM aluno 2)

Perguntado ainda quais atividades deveriam estar mais presentes nas aulas, $45 \%$ dos alunos responderam que deveriam ter mais jogos e gincanas; $45 \%$ afirmaram a necessidade de relacionar os conteúdos com músicas e vídeos e $10 \%$ responderam que deveria ter mais leitura. Ainda nesta pergunta, os alunos completaram com as seguintes afirmativas:

[...] necessita-se de gincanas que estimulem a competitividade e melhorem a mente (EM aluno 28)

[...] espero que após a pesquisa as aulas sejam mais criativas e animadas, que os professores tragam mais objetos para explicar a aula, gostaria que tivesse mais variedades e não fosse a mesma aula todos os dias (EM aluno 19)

[...] gostaria de ter aula de pintura em tela, aulas fora do colégio são legais, menos teoria e mais prática, mais intervenções, mais atividades esportivas, aulas mais dinâmicas e culturais, atividades externas como teatro e museus (EP aluno 17)

As afirmativas dos alunos do Ensino Médio e do Ensino Profissionalizante indicam que os alunos desejam atividades mais dinâmicas e interativas que oportunizem a participação durante todo o processo de ensino. Estas estratégias melhoram o interesse pelo conteúdo, o que pode resultar numa possibilidade de uma melhora no aprendizado e na qualidade do ensino.

Corroborando com essa necessidade que os alunos demonstraram de se ter nas aulas ações pedagógicas centradas em práticas interativas ou jogos pedagógicos, encontra-se em Cunha (1988) a justificativa para inserir o jogo pedagógico nas aulas, pois o autor afirma que o jogo pedagógico ou didático tem sempre como objetivo proporcionar determinadas aprendizagens, diferenciando-se do material pedagógico, podendo conter o aspecto lúdico, possibilitando maior interesse e integração por parte dos alunos.

Após as atividades propostas no projeto de intervenção com jogos e brincadeiras pedagógicas, questionamos os alunos acerca de como se deu a aprendizagem utilizando essa metodologia: $71 \%$ disseram que aprendizagem por meio do lúdico significou aprender brincando de uma forma divertida; $22 \%$ afirmaram que aprenderam ouvir o professor; $7 \%$ disseram que não interferiu na forma de aprender o conteúdo. Esses resultados nos levam a entender que após as intervenções torna-se possível pensar em umtrabalho pedagógico que rompa com a ação fragmentada das disciplinas que por vezes acontece de forma individualizada.

[...] o sistema escolar produziu e continua reproduzindo suas disciplinas, sua seriação, suas grades; e se limita a ensinar suas próprias produções e a aprovar ou reprovar a partir de critérios de procedência que ele mesmo definiu como mínimos para transitar no seu próprio curso, percurso escolar (ARROYO, 1992, p. 50).

Esse trabalho individualizado pode ser alterado quando a ação pedagógica dos professores integrou os conteúdos escolares, mesmo obedecendo à grade escolar, com disciplinas distintas, os conteúdos se cruzaram permitindo aos alunos compreenderem como se integram sendo possível levá-los para as reflexões cotidianas.

Quando questionados acerca da importância dos jogos e brincadeiras pedagógicas trabalhadas em sala de aula, 93\% afirmaram que os jogos foram muito importantes para compreender os conteúdos, facilitando o entendimento; $50 \%$ relataram que os jogos e brincadeiras facilitaram a aprendizagem; $43 \%$ disseram que aprenderam se divertindo; $7 \%$ relataram que apenas se divertiram, mas não aprenderam os conteúdos; e menos de $1 \%$ que sentiram dificuldades em conhecer os conteúdos por meio dos jogos e brincadeiras pedagógicas. 
[...] as atividades lúdicas facilitam o aprendizado (EP aluno 21)

[...] estimulam o interesse, proporciona a aula uma energia boa, torna mais didática, distrai a mente e fornece mais animação, fixam melhor o conteúdo, aprendemos nos divertindo (EM aluno 8)

[...] aula "massa", muito legal, empolgante, os professores cativam mais os alunos, é mais fácil de aprender, aprendi sem decorar, as aulas foram mais práticas e dinâmicas, aí presto mais atenção nos professores (EM aluno 22)

[...] saiu um pouco do "clima do quadro" e não deixamos de aprender, não ficou tão "massante", as aulas que envolveram toda a sala, saiu da monotonia, não se deve ficar na rotina, ela cansa (EM aluno 21)

[...] é gostoso usar a imaginação, envolve mais a atenção de todos. As aulas são legais e com jogos ficam mais legais ainda, o aluno consegue se soltar, sai da repetição, transmite o conteúdo de maneira simples e divertida, não ficamos entediados somente copiando (EP aluno 9)

[...] aula lúdica "quebra o sistema", mas para ter um bom aproveitamento deve ser bem organizado e levado a sério por parte de todos, exige cooperação e seriedade, todos se divertem, mas não podem ultrapassar o limite, aí conseguem diferenciar das outras aulas, que são cansativas, às vezes é bom desligar um pouco do "automático", se for demais fica chato, nem todas as matérias se encaixam no lúdico, não precisa fazer sempre, mas facilita aprender (EP aluno 17).

Ao término da intervenção, com o trabalho dos conteúdos por meio dos jogos e brincadeiras, questionamos sobre a interação do professor e novamente sobre como os alunos compreendem o papel dos professores. Os resultados foram significativos, pois demonstraram que houve também uma mudança no olhar do aluno para com os professores, conforme os depoimentos:

[...] é muito bom ter aulas com professores que sabem dos conteúdos, que conhecem o que ensinam (EM aluno 9)

[...] é bem bacana ter aula com professores que ensinam de forma divertida é bem mais simples e fácil de aprender (EM aluno 19)

[...] os professores são muito legais, eles escutam o que a gente diz, e até aceitam outras ideias, isso é muito legal (EP aluno 14)

[...] nossa as aulas desse ano com os mesmos professores foram muito melhores, dá mais vontade de vir pra escola, porque é sempre uma boa surpresa, a gente nunca sabe o que vai acontecer, mas de um jeito legal (EP aluno 11)

[...] com esses professores dá até vontade de aprender (EP aluno 8)

Para verificarmos os resultados das aulas, que utilizaram no trimestre os jogos e as brincadeiras pedagógicas para o trabalho com os conteúdos escolares, e entendermos se o processo avaliativo apresentaria diferenças entre a metodologia de aulas expositivas, comparada ao uso de jogos e brincadeiras pedagógicas, os professores afirmaram que a metodologia proporcionou uma melhoriana participação dos alunos em aula em 68\%, quando comparados com o modelo de ensino, seguindo o modelo estabelecido pelo Projeto Pedagógico da escola. Também obtivemos um aumento na média das notas, ou seja, a maioria dos alunos aumentou em 15\% a mais suas notas em comparação com o trimestre anterior quando os conteúdos foram centrados no modelo expositivo de aulas.

Ainda de acordo com os professores, ao utilizarem os jogos e as brincadeiras pedagógicas nas suas aulas, obteve-se um maior dinamismo para com os conteúdos, o que refletiu em alunos mais interessados e participativos, evidenciando a maior interação entre todos, enaltecendo o trabalho coletivo tanto para o ensino médio como para o ensino profissionalizante. 


\title{
Considerações finais
}

O ensino por meio do lúdico não finaliza em si mesmo, mas nos possibilitou perceber que pode ser uma estratégiapedagógica que auxilia os professores a alcançar seus objetivos junto aos alunos, além motivá-los a interagirem de maneira mais efetiva com os conteúdos. Trabalhar de maneira integrada com as disciplinas permite ampliar a análise dos alunos, a olhar para os conteúdos de forma articulada e não meramente fragmentos de conhecimentos desconexos entre si e sem relação com a vida cotidiana.

A interação entre as disciplinas, professores, eentre professores e alunos possibilitou que houvesse um maior interesse por parte dos alunos com relação aos conteúdos escolares, gerando mudanças na relação professor-aluno. Entre os professores, evidenciou-se que o planejamento coletivo possibilita uma maior integração entre as disciplinas e uma aprendizagem mais efetiva.

Demonstrou ainda que os professores se sentiram motivados a buscar outras estratégias de ensino. Afinal, a participação dos alunos os motivaram a buscar uma forma diferenciada para trabalhar com os conteúdos escolares. Um planejamento coletivo dos professores permite uma melhoria na qualidade da/na educação, uma vez que fortalece o trabalho em equipe e desperta o compromisso com o coletivo. $\mathrm{O}$ trabalho com o jogo e com a brincadeira pedagógica permitiu aos professores se adaptarem a essa ferramenta educacional que pode ser utilizada na construção do conhecimento, enriquecendo a dinâmica escolar e favorecendo o ensino-aprendizagem.

Quanto aos alunos, os mesmos defendem que a escola necessita de maior dinamicidade, de valorização das potencialidades e apontam para o desejo de que atividades lúdicas aconteçam com maior frequência para a fixação do conteúdo ministrado. Evidenciaram que se sentem mais desafiados quando a rotina escolar é diversificada, tornando-a mais atrativa, gerando alunos mais comprometidos com os saberes curriculares.

A experiência vivenciada mostrou que é possível avançar rumo a uma educação de qualidade, mas para tanto, é preciso que haja mudanças na prática docente de maneira coletiva, a fim de que todos os atores envolvidos na cena possam contracenar no mesmo objetivo e direção.

\section{FROM THE EDUCATIONAL ACTION TO THE CHANGE IN TEACHING PRAC- TICE: GAMES AND PLAYS IN AN EXPERIENCE WITH SECONDARY EDUCA- TION}

\begin{abstract}
This research aims to present the results of an interdisciplinary action with high school teachers in a public school of Northwest Paraná, focusing on the reflections and changes brought about in teaching practice when working the school subjects through games and play. A focal group with teachers from different subjects was developed, in which the discussions directed to a possibility of intervention and application of content through games. At first, the students indicated that the classes and contents were tiring and learning was difficult. With the use of games and plays, greater dynamism was given to the classes resulting in greater interest of students, showing that when the teacher gives opportunity of participation and interaction, students become more interested, encouraging the collective work.
\end{abstract}

Keywords: School Physical Education. Pedagogical Action. Teaching-Learning Process. 


\section{DE LA ACCIÓN EDUCATIVA ALATRANSFORMACIÓNDE LA PRÁCTICA DO- CENTE: LOS JUEGOS Y LAS RECREACIONES EN UNA EXPERIENCIA CON LA EDUCACIÓN SECUNDARIA}

\section{Resumen}

El objetivo de este estudio fue presentar los resultados del trabajo interdisciplinar desarrollado con los profesores de Enseñanza Secundaria de un colegio del Noroeste de Paraná, el trabajo giró en torno a las reflexiones y transformaciones originadas en la práctica docente a partir del trabajo con juegos y recreaciones. Se formó un grupo focal con profesores de diferentes asignaturas, en el que los debates se direccionaron a la posibilidad de intervención y aplicación de los contenidos por intermedio de la recreación. Inicialmente los estudiantes decían que las clases y los contenidos eran agotadores y que el aprendizaje se hacía difícil, ya con el uso de los juegos y recreaciones se obtuvo más dinamismo, resultando en más interés por parte de los alumnos en la clases, demostrando que cuando, los alumnos, tienen más oportunidades para participar e interactuar se integran e interesan más, enalteciendo el trabajo colectivo.

Palabras clave: Educación Física Escolar. Acción Pedagógica. Proceso de EnseñanzaAprendizaje.

\section{Referências}

ALVES, G. L. O trabalho didático na escola moderna: formas históricas. Campinas, SP: Autores Associados, 2005.

ARROYO, M. G. Fracasso-sucesso: o peso da cultura escolar e do ordenamento da educação básica. Em Aberto, Brasília, ano 11, n. 53, p. 46-53, jan./mar. 1992.

BARROS, A. J. P., LEHFELD, N. A. de S. Fundamentos de metodologia: um guia para a iniciação científica. 3. ed. São Paulo: Makron Books, 2000.

CHIZZOTTI, A. Pesquisa qualitativa em ciências humanas e sociais. Petrópolis, RJ: Vozes, 2006.

CORREA, L. M.; SOUZA, M. C. R. F.; BICALHO, M. G. P. Os significados que jovens e adultos atribuem à experiência escolar. In: REUNIÃO ANUAL DA ANPED, 2003, Caxambu. Anais da 26a Reunião Anual da ANPED, Caxambu, 2003.

CUNHA, N. Brinquedo, desafio e descoberta. Rio de Janeiro, RJ: FAE, 1988.

CUNHA, M. B. Jogos no Ensino de Química: Considerações Teóricas para sua Utilização em Sala de Aula. Química Nova na Escola, São Paulo, v. 2, n. 2, p. 92-98, mai. 2012.

DANTAS, M. B. da S.; PAIVA, M. de O.; BARBOSA JÚNIOR, W. P. O PROEJA no estado do Rio Grande do Norte: possibilidades e limites. Natal, RN: Editora do CEFET, 2007.

DARIDO, C. D. et al. Educação Física no Ensino Médio: reflexões e ações. MOTRIZ, Rio Claro, v. 5, n. 2, p. 138-145, dez. 1999.

FARIA, D. S. A.; MOURA, D. H. Desistência e permanência de estudantes de ensino médio do proeja. HOLOS, Rio Grande do Norte, ano 31, v. 4, p. 151-165, 2015. 
FRIEDMANN, A. Brincar: crescer e aprender - o resgate do jogo infantil. São Paulo: Moderna, 1996.

GATTI, Bernardete Angelina. Grupo focal na pesquisa em Ciências sociais e humanas. Brasília: Líber Livro, 2005.

HUIZINGA, J. Homo ludens: o jogo como elemento de cultura. Tradução de João Paulo Martins. São Paulo: Perspectiva, 1980.

IVIC, I.; COELHO, E. P. Lev Semionovich Vygotsky. Recife: Fundação Joaquim Nabuco, Ed. Massangana, 2010.

KISHIMOTO, T. Jogo, brinquedo, brincadeira e a educação. 8. ed. São Paulo: Cortez, 2005.

NASCIMENTO, R. M. et al. Lúdico como ferramenta pedagógica no processo ensino aprendizagem. Revista perspectivas online: biol. e saúde, Campos dos Goitacazes, v. 2, n. 5, p. 23-30, 2012.

PALMA, M.S. et al. Jogos tradicionais no contexto educativo. Kinesis, v. 33, n. 2, p. 99-113, 2015.

PIMENTEL, S. C. O especial dos jogos e brincadeiras no atendimento as diferenças. Revista da FAEEBA - Educação e Contemporaneidade, Salvador, v. 15, n. 25, p. 147-156, jan./jun., 2006;

REGO, T. C. Configurações sociais e singularidades: o impacto da escola naconstituição dos sujeitos. In: OLIVEIRA, M. K. de; SOUZA, D. T. R.; REGO, T. C. (Orgs.). Psicologia, educação e as temáticas da vida contemporânea. São Paulo: Moderna, 2002.

ROJAS, R. A. O. El Cuestionario, 2001. Disponível em: <http://www.nodo50.org/sindpitagoras/Likert.htm> Acesso em: 02 abr. 2016.

SANTANA, E. M. O uso do jogo autódromo alquímica como mediador da aprendizagem no ensino de química. 2012. 173 f. Dissertação de Mestrado - Universidade Estadual de São Paulo, Faculdade de Educação, Instituto de Física, Química e Biociências, São Paulo, 2012.

SANTOS, L. P. C. P. Dilemas e perspectivas na relação entre ensino e pesquisa. In: ANDRÉ, Marli (Org.). O papel da pesquisa na formação e prática dos professores. 5. ed. Campinas, SP: Papirus, 2006a. p. 11-26.

SANTOS, M. J. E. Ludicidade e educação emocional na escola: Limites e possibilidades. Revista da FAEEBA - Educação e Contemporaneidade, Salvador, v. 15, n. 25, p. 27-41, jan./jun. 2006b.

VIGOTSKI, L. S. A formação social da mente. São Paulo: Martins Fontes, 1998. 
Aprovado em: 28/09/2016

Endereço para correspondência:

ana.beah@gmail.com

Ana Luiza Barbosa Anversa

Universidade Estadual de Maringá, Centro de Ciências da Saúde

Avenida Colombo, 5790

Centro

87020-900 - Maringá, PR - Brasil 